\title{
Associação do número diário de refeições com parâmetros antropométricos em crianças
}

Fernanda Martins de Albuquerque, Mariana de Santis Filgueiras, Luana Cupertino Milagres, Naruna Pereira Rocha, Ana Paula Pereira Castro, Juliana Farias de Novaes

\section{Resumo}

Com a rápida mudança do padrão alimentar e do estilo de vida decorrente do processo de transição nutricional, observa-se o aumento da prevalência de excesso de peso na população infantil em diversas partes do mundo, com repercussões sobre a situação da saúde e qualidade de vida das crianças. A fase escolar é caracterizada por intensas atividades e este ritmo muitas vezes prejudica $\mathrm{o}$ fracionamento das refeições durante o dia. A omissão de refeições é prejudicial uma vez que o maior fracionamento destas proporciona uma maior saciedade e aumenta o gasto energético auxiliando no controle do peso corporal. Avaliar a associação do número diário de refeições com parâmetros antropométricos em crianças de Viçosa-MG. Trata-se de um estudo transversal realizado com 378 crianças de ambos os sexos com idade de 8 e 9 anos, matriculadas em escolas públicas e privadas da zona urbana de Viçosa-MG. Foram aferidos peso e estatura e essas medidas foram utilizadas para o cálculo do Índice de Massa Corporal (IMC). O perímetro da cintura (PC) foi aferido no ponto médio entre a crista ilíaca e a última costela. O número médio de refeições diárias foi obtido somando-se o número de refeições realizadas em três dias não consecutivos por meio da aplicação do recordatório alimentar de 24 horas e calculando-se a média final dos três dias. A análise estatística foi realizada no software SPSS versão 20, sendo considerado o nível de significância estatística de 5\%. Este estudo foi aprovado pelo Comitê de Ética em Pesquisa com Seres Humanos da Universidade Federal de Viçosa. Crianças que realizavam três ou menos refeições por dia tiveram maiores medianas de IMC $\left(23,4 \mathrm{~kg} / \mathrm{m}^{2}\right)$ e PC $(69,1 \mathrm{~cm})$ em relação àquelas que realizavam mais de três refeições diárias $\left(69,1 \mathrm{~kg} / \mathrm{m}^{2}\right.$ e $57,5 \mathrm{~cm}$, respectivamente) $(\mathrm{p}<0,05)$. Verifica-se que crianças com um menor fracionamento das refeições apresentaram maiores valores de IMC e PC. Esse resultado sugere haver uma associação do número de refeições realizadas por dia com o excesso de peso infantil. Ações de reeducação alimentar e nutricional devem ser realizadas de forma precoce para prevenção da obesidade e de comorbidades associadas. Além dos serviços de saúde, as escolas configuram-se como um ambiente propício para o desenvolvimento destas ações para a promoção de hábitos alimentares saudáveis.

Descritores: Obesidade; Criança; Educação alimentar e nutricional. 